\title{
A Novel Micro-Scale Plastic Deformation Feature on a Bulk Metallic Glass Surface under Laser Shock Peening*
}

\author{
WEI Yan-Peng(魏延鹏) $)^{1}$, WEI Bing-Chen(魏炳忱 $)^{2}$, WANG Xi(王曦) ${ }^{1}$, XU Guang-Yue(徐光跃 $)^{2}$, \\ LI Lei(李否 $)^{3}$, WU Xian-Qian(吴先前 $)^{1}$, SONG Hong-Wei(宋宏伟 $)^{1}$, HUANG Chen-Guang(黄晨光) ${ }^{1 * *}$ \\ ${ }^{1}$ Key Laboratory for Mechanics in Fluid-Solid Coupling Systems, Chinese Academy of Sciences, Beijing 100190 \\ ${ }^{2}$ Key Laboratory of Microgravity (National Microgravity Laboratory), Institute of Mechanics, Chinese Academy of \\ Sciences, Beijing 100190 \\ ${ }^{3}$ Sinosteel Corporation, Beijing 100190
}

(Received 15 November 2012)

\begin{abstract}
Laser shocking peening is a widely applied surface treatment technique that can effectively improve the fatigue properties of metal parts. We observe many micro-scale arc plastic steps on the surface of $\mathrm{Zr}_{47.9} \mathrm{Ti}_{0.3} \mathrm{Ni}_{3.1} \mathrm{Cu}_{39.3} \mathrm{Al}_{9.4}$ metallic glass subjected to the ultra-high pressure and strain rate induced by laser shock peening. The scanning electronic microscopy and atomic force microscopy show that the arc plastic step (APS) has an arc boundary, 50-300 $\mathrm{nm}$ step height, 5-50 $\mu \mathrm{m}$ radius and no preferable direction. These APSs have the ability to accommodate plastic deformation in the same way as shear band. This may indicate a new mechanism to accommodate the plastic deformation in amorphous metallic glass under high pressure, ultra-high strain rates, and short duration.
\end{abstract}

\section{PACS: 62.20.fq, 62.50.Ef, 81.40.Np～DOI: $10.1088 / 0256-307 \mathrm{X} / 30 / 3 / 036201$}

As one of the most promising structural materials, bulk metallic glasses (BMGs) have drawn much attention due to their unique properties such as high strength/weight ratio and large elastic deformation capability. ${ }^{[1-3]}$ Recently, in order to improve the performance in specific application areas, several surface modification methods have been applied on BMGs. For example, sand blasting ${ }^{[4]}$ is used to improve the wettability of BMG for biomedical applications. Laser melting is utilized to induce residual stress ${ }^{[5]}$ or to form nano-crystals ${ }^{[6]}$ in a subsurface to improve the mechanical properties. Zhang et al. ${ }^{[7]}$ successfully treated a BMG's surface with shot peening to generate a $\sim 80-\mu \mathrm{m}$-thick affected zone which contained many slight shear bands. It is speculated that these pre-existing shear bands are favored locations for resumed plastic flow, so that the plasticity is increased while fewer main shear bands are generated. Similar to but having more advantages over shot peening, laser shock peening (LSP) ${ }^{[8]}$ has been widely used to improve wear resistance and fatigue performance in the metallic components of bulk materials. In the LSP process, a shock wave is generated and propagates into the target through the interaction of a pulsed high-intensity laser beam and absorption layer on the metallic target surface. If the amplitude of the shock wave exceeds the Hugoniot elastic limit (HEL) of the target material, plastic deformation occurs and residual compressive stresses are induced near the material surface, resulting in the enhancement of fatigue life. Since the beam size could be easily adjusted, a localized micro-scale peening technique ${ }^{[9]}$ has been developed and applied on the metal films in the semiconductor industry. In addition, LSP is suitable in processing materials with complex structural geometry by manipulating laser beams and utilizing liquid confining media like water. ${ }^{[10]}$ To our knowledge, LSP processing on BMGs is rarely reported. In this Letter, we report a novel micro-scale plastic deformation feature observed on the surface of Zr-BMG treated by LSP.

A $\mathrm{Zr}_{47.9} \mathrm{Ti}_{0.3} \mathrm{Ni}_{3.1} \mathrm{Cu}_{39.3} \mathrm{Al}_{9.4}$ BMG rod in diameter $5 \mathrm{~mm}$ was prepared by melting a mixture of elemental metals with purities ranging from $99.5 \%$ to 99.99\% in an argon atmosphere and chill-casting into a copper mold. ${ }^{[11]}$ Structural characterizations by x-ray diffraction (XRD) confirmed its amorphous structure. The BMG rod was cut into disks with the thickness of about $5 \mathrm{~mm}$ and both sides of the disk specimen were manually ground and polished by using a standard metallographic process. Figure 1(a) shows the schematic diagram for the LSP experiments. A 50$\mu \mathrm{m}$-thick self-adhesive aluminum foil used as an ablative overlay to absorb the laser energy was attached to the surface of the BMG disk. A 4-mm-thick BK-7 glass is placed on top of the aluminum foil as a confined layer to constrain the plasma generated by the laser irradiation. The confined overlay, the absorption layer, and the specimen were firmly pressed together during the experiment. The laser pulse was generated

\footnotetext{
* Supported by the National Natural Science Foundation of China under Grant No 11002150, the Basic Research Equipment Project of the Chinese Academy of Sciences under Grant No YZ200930, and the National Basic Research Program of China under Grant No 2007CB613905.

** Corresponding author. Email: weiyanpeng@imech.ac.cn

(C) 2013 Chinese Physical Society and IOP Publishing Ltd
} 
by a $Q$-switched high power Nd:YAG pulse laser with a wavelength of $1064 \mathrm{~nm}$. The energy of a single laser pulse is about $2.35 \mathrm{~J}$ and the full width at half maximum (FWHM) is approximately $10 \mathrm{~ns}$. The original laser beam size is about $12 \mathrm{~mm}$ in diameter and a focusing lens was used to adjust the beam size to $2 \mathrm{~mm}$ such that the laser intensity was above $7 \mathrm{GW} / \mathrm{cm}^{2}$ at the specimen surface. The indent surface was examined with a high resolution scanning electronic microscope (FEI-Sirion NC HRSWM) and an atomic force microscope (AFM).

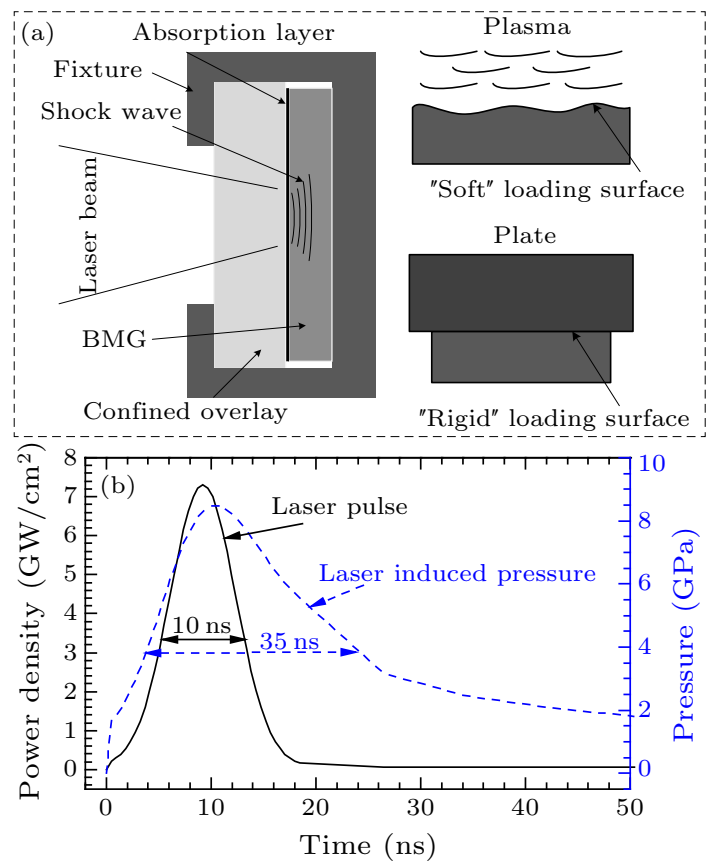

Fig. 1. (a) Schematic diagram for LSP experiments and the comparison of a "soft" loading surface and a "rigid" loading surface. (b) Laser power density and induced pressure profile.

An indent with the diameter of $\sim 1.8 \mathrm{~mm}$ was observed at the peened surface of Zr-based BMG after laser shock, which indicates that the material has undergone plastic deformation. Numerous localized plastic deformation regions (as shown in Fig. 2(a)) were observed on the shock treated surface. The edge of these localized plastic deformation regions always presents as an arc shape and has a altitude difference from surroundings. We named those arc shape features as arc plastic steps (APSs). These APSs have no preferred direction, in contrary to a certain direction in shear band propagation. ${ }^{[12]}$ The estimated radius of APSs varies from $5 \mu \mathrm{m}$ to $50 \mu \mathrm{m}$, and the step height ranges from $50 \mathrm{~nm}$ to $300 \mathrm{~nm}$ from AFM measurements. A few APSs exist individually with a perfect circle shape (as shown in Fig. 2(b)) and the diameter of the single APS is about $12 \mu \mathrm{m}$. Those APSs form overlapped, connected or layered patterns as shown in Fig. 2(c). Figure 2(d) shows a region of multiple interacting APSs, which indicates that this region ex- perienced severe localized plastic deformation. Moreover, parallel shear bands are also observed co-existing with the APS on the shocked surface (as shown in Fig. 2(e)). The starting side of shear bands connects with an APS seamlessly and the ending side shows several micro branches, as reported in Refs. [13,14]. Typical AFM results are shown in Fig. 3. The step height of APSs close to the shear band is much lower than that of those away from the shear band $(52 \mathrm{~nm}$ vs $300 \mathrm{~nm}$, average of 5 measurements from AFM).

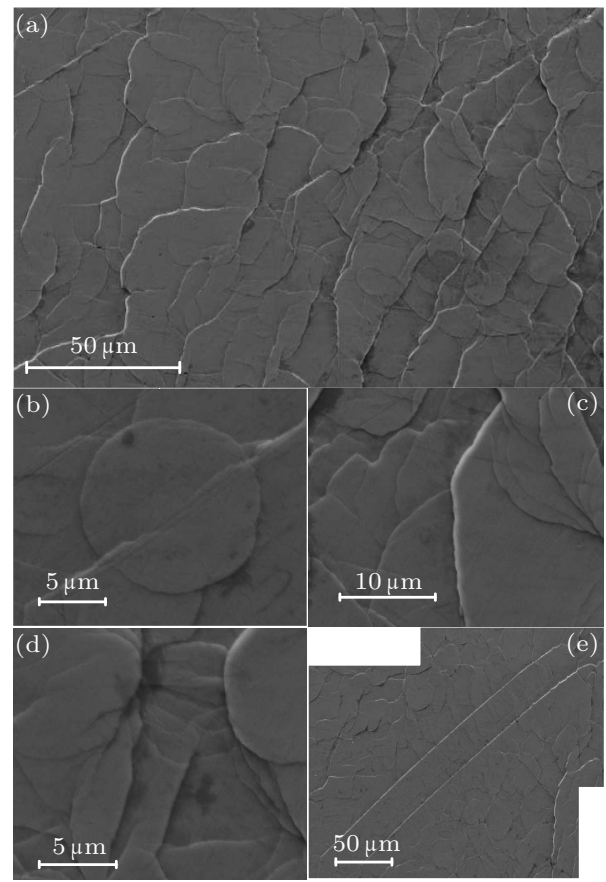

Fig. 2. Scanning electronic microscopy (SEM) of the treated surface of the $\mathrm{Zr}_{47.9} \mathrm{Ti}_{0.3} \mathrm{Ni}_{3.1} \mathrm{Cu}_{39.3} \mathrm{Al}_{9.4}$ specimen. (a) Lower-magnification images of APSs, (b) perfect circle APS, (c) combined APS, (d) multiplex APS, (e) shear bands.
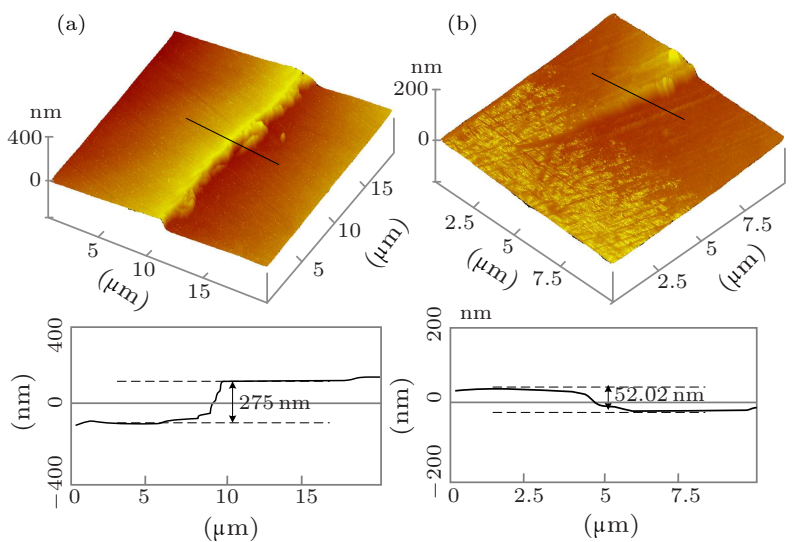

Fig. 3. AFM images of a treated surface of $\mathrm{Zr}_{47.9} \mathrm{Ti}_{0.3} \mathrm{Ni}_{3.1} \mathrm{Cu}_{39.3} \mathrm{Al}_{9.4}$ specimen. (a) APS step height beyond shear bands. (b) APS step height near shear bands.

The formation of APS on the surface of BMGs depends on the loading conditions in LSP. By using a coupling pressure analytical method, ${ }^{[15]}$ the pressure 
transmitted into the BMG through a shock wave was estimated to have a peak value of about $8.2 \mathrm{GPa}$ and an FWHM of about 35 ns (as shown in Fig. 1(b)). The maximum strain rate during LSP can be estimated by

$$
\dot{\varepsilon}=\frac{\dot{\sigma}}{E},
$$

where $\dot{\sigma} \approx 2.3 \times 10^{8} \mathrm{GPa} / \mathrm{s}$ is the stress loading rate derived from the rising edge of pressure pulse and $E \approx 90 \mathrm{GPa}$ is elastic modulus of $\mathrm{Zr}$-based BMG. The maximum strain rate is estimated to be about $2.5 \times 10^{6} \mathrm{~s}^{-1}$. This strain rate and pressure level is comparable to the plate impact experiments in which no such APS was observed. ${ }^{[16-19]}$ There are two causes that preserve the APSs on the surface of BMG after laser shock peening. First, different from the rigid loading surface in plate impact experiments where the displacement of the material surface is constrained by the flyer, LSP has a kind of soft loading surface where the surface of material deforms under the pressure control mode (as illustrated in Fig. 1(a)). Second, in plate impact experiments, BMGs were often impacted by a flyer carrying a great deal of kinetic energy $(\sim 500 \mathrm{~J})^{[17]}$ and were broken into pieces after the impact. The difficulty of recovering the original specimen limits the direct observation of plastic deformation. In contrast, in LSP we can precisely regulate the input energy to ensure the integrity of the plastic region without crack generation.

As shown in Fig. 3(e), a few shear bands are also observed in the shocked zone. Shear bands are known as the main way to accommodate plastic deformation of amorphous materials at room temperature. ${ }^{[3]}$ At high strain rate $\left(\sim 10^{6} \mathrm{~s}^{-1}\right)$ and very short duration ( $\sim 30 \mathrm{~ns})$, the shear band nucleation and growth could be suppressed. ${ }^{[20,21]}$ However, the APSs have a relative small geometrical dimension $(\sim 10 \mu \mathrm{m})$, which is more easily generated in a short time. Meanwhile, the APSs can interact with each other in a local plastic region, so that more plastic deformation could be accommodated. The APSs co-exist with the shear band, but the step height of APS close to the shear band is much lower than those away from the shear band. When the shear band initiates and propagates, the stress level drops near ${ }^{[22,23]}$ where the APS has no sufficient driving force to grow and stays in a small length scale. To accommodate the large plastic deformation induced by the ultra-high pressure, a limited number of shear bands is insufficient and these small APSs become a compensation mechanism. In regions where no shear band appears, the APSs are the main way to accommodate the plastic deformation. A widely acceptable view is that the initiation of a shear band is always characterized as load drop in the stress-strain curve during uniaxial compression. These nonuniform plastic flows are depicted as a "serrated flow". ${ }^{[22,24]}$ There are similar mechanical hints for the initiation of plastic deformation during high pressure, high strain rate, and short duration. Turneaure et al. ${ }^{[18]}$ and Yuan et $a l .{ }^{[19]}$ observed an obvious load drop in the Hugoniotcompression curves in plate impact experiments. It is speculated that the APSs could be activated simultaneously when the stress exceeds the HEL of BMGs, which causes the instantaneous stress relaxation in the Hugoniot-compression curves.

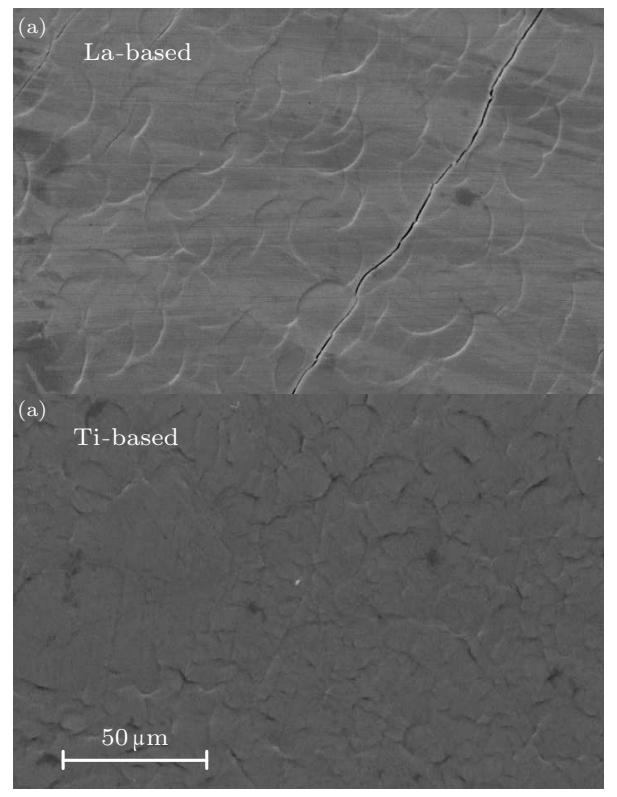

Fig. 4. SEM images of treated surface of (a) La-based and (b) Ti-based BMGs.

The APS is not an exclusive deformation mode for Zr-based BMGs, which is also observed on the surface of La-based and Ti-Based BMGs after LSP (as shown in Fig. 4). The microscopic mechanism of APS may be related to the nanoscale inhomogeneous structure in BMGs. ${ }^{25,26]}$

In summary, a laser shock peening experiment has been carried out on $\mathrm{Zr}_{47.9} \mathrm{Ti}_{0.3} \mathrm{Ni}_{3.1} \mathrm{Cu}_{39.3} \mathrm{Al}_{9.4}$ bulk metallic glasses. The SEM and AFM results show that numerous arc plastic steps (APSs) appear on the shock treated surface. The APSs show an arc shape boundary, a 50-300 $\mathrm{nm}$ step height, a $5-50 \mu \mathrm{m}$ radius, and no preferred direction. These features are different from traditional shear bands. The APS is not an exclusive deformation mode for Zr-based BMGs, which is also observed on the surface of La-based and Ti-Based BMGs after LSP. It may be a new mechanism to accommodate the plastic deformation under extremely high pressure, high strain ratem and short duration.

\section{References}

[1] Chen M W 2011 Npg. Asia Mater. 382

[2] Wang W H 2009 Adv. Mater. 214524

[3] Spaepen F 2006 Nat. Mater. 57 
[4] Li H F, Wang Y B, Zheng Y F and Lin J P 2012 J. Biomed. Mater. Res. B 1001721

[5] Chen B Q, Li Y, Yi M, Li R, Pang S J, Wang H and Zhang T 2012 Scr. Mater. 661057

[6] Wu G J, Li R, Liu Z Q, Chen B Q, Li Y, Cai Y and Zhang $\mathrm{T} 2012$ Intermetallics $\mathbf{2 4} 50$

[7] Zhang Y, Wang W H and Greer A L 2006 Nat. Mater. 5 857

[8] Peyre P and Fabbro R 1995 Opt. Quantum Electron. 27 1213

[9] Guo Y B and Caslaru R 2011 J. Mater. Process. Tech. 211 729

[10] Reitz W 2002 Surf. Eng. 181

[11] Wei B C, Zhang T H, Zhang L C, Xing D M, Li W H and Liu Y 2007 Mat. Sci. Eng. A 449962

[12] Gao Y F, Wang L, Bei H and Nieh T G 2011 Acta Mater. 594159

[13] Liu L F, Dai L H, Bai Y L, Wei B C and Eckert J 2005 Mater. Chem. Phys. 93174

[14] Lee J Y, Han K H, Park J M, Chattopadhyay K, Kim W T and Kim D H 2006 Acta Mater. 545271

[15] Wu X, Huang C, Wang X and Song H 2011 Int. J. Impact Eng. 38322

[16] Turneaure S J, Winey J M and Gupta Y M 2004 Appl.
Phys. Lett. 841692

[17] Meng J X, Ling Z, Jiang M Q, Zhang H S and Dai L H 2008 Appl. Phys. Lett. 92171909

[18] Mashimo T, Togo H, Zhang Y, Uemura Y, Kinoshita T, Kodama M and Kawamura Y 2006 Appl. Phys. Lett. 89 241904

[19] Yuan F, Prakash V and Lewandowski J J 2007 J. Mater. Res. 22402

[20] Schuh C A, Lund A C and Nieh T G 2004 Acta Mater. 52 5879

[21] Schuh C A and Nieh T G 2004 J. Mater. Res. 1946

[22] Dalla Torre F H, Klaumuenzer D, Maass R and Loeffler J F 2010 Acta Mater. 583742

[23] Jiang W H, Pinkerton F E and Atzmon M 2005 Acta Mater. 533469

[24] Georgarakis K, Aljerf M, Li Y, LeMoulec A, Charlot F, Yavari A R, Chornokhvostenko K, Tabachnikova E, Evangelakis G A, Miracle D B, Greer A L and Zhang T 2008 Appl. Phys. Lett. 93031907

[25] Fujita T, Konno K, Zhang W, Kumar V, Matsuura M, Inoue A, Sakurai T and Chen M W 2009 Phys. Rev. Lett. 103 075502

[26] Liu Y H, Wang G, Wang R J, Zhao D Q, Pan M X and Wang W H 2007 Science 3151385 